\title{
Jumps Beyond the Realms of Cricket: India's Performance in One Day Internationals and Stock Market Movements*
}

\author{
Konstantinos Gkillas \\ Department of Business Administration, University of Patras, \\ University Campus, Rio, P.O. Box 1391, 26500 Patras, Greece. \\ Email: gillask@upatras.gr \\ Rangan Gupta \\ Department of Economics, University of Pretoria, \\ Pretoria, 0002, South Africa. \\ Email: rangan.gupta@up.ac.za \\ Chi Keung Marco Lau \\ Huddersfield Business School, University of Huddersfield, \\ Huddersfield, HD1 3DH, United Kingdom. \\ Email: c.lau@hud.ac.uk \\ Muhammad Tahir Suleman \\ Department of Financial and Business Analysis, \\ Lincoln University, Christchurch., New Zealand. \\ Email: Muhammad.Suleman@lincoln.ac.nz
}

\begin{abstract}
We examine the impact of the Indian cricket team's performance in one-day international cricket matches on return, realized volatility and jumps of the Indian stock market, based on intraday data covering the period of 30th October, 2006 to 31st March, 2017. Using a nonparametric causalityin-quantiles test, we were able to detect evidence of predictability from wins or losses for primarily volatility and jumps, especially over the lower-quantiles of the conditional distributions, with losses having stronger predictability than wins. However, the impact on the stock return is weak and restricted towards the upper end of the conditional distribution.
\end{abstract}

Keywords: Investor psychology, Cricket, India, Stock market movements JEL Codes: C22, G1

\footnotetext{
${ }^{*}$ We would like to thank the Associate Editor and an anonymous referee for many helpful comments. However, any remaining errors are solely ours.
} 


\section{Introduction}

"Game's soul is not at Lord's. It is here." - Michael A. Atherton. ${ }^{1}$

Following Baker and Wurgler [2006], there is an extensive literature on the impact of investors' and corporate managers' sentiments on movements in stock prices (see, Huang, Jiang, and Zhou [2015], Jiang, Lee, Martin, and Zhou [2018], and Zhou [2018] for detailed discussions of this literature). Related to this line of research, several recent studies in behavioral finance tends to suggest that the sentiments of viewers cum investors are affected by the performance of the team they support in their favorite sports, which in turn, leads to upwards or downwards "mood swings" in the market and are reflected in stock prices.

This is an interesting finding, since a sporting event is a noneconomic phenomenon and hence, if the Efficient Market Hypothesis (EMH) does hold, one should not expect any impact on stock prices. However, the explanation for this observation can be drawn from neuroeconomics, whereby economists rely on the psychology literature which examines the impact of mood fluctuations on the decision making process. Formally speaking, the argument can be outlined as follows: the human brain has four lobes known as frontal, parietal, occipital and temporal. The frontal lobe performs the functions of planning, cognitive control and integration of cross-brain input, while the parietal lobe governs motor action. The occipital lobe is used for visual processing, and finally, the temporal lobe controls memory, recognition and emotion. While these different parts of the brain have different functions, neurons from different areas are interconnected in order to enable the brain to respond to complex stimuli in an integrated manner. If all economic decisions were made by the frontal lobe of the brain, then all of them would conform to the rational utility maximization, however, because of the interaction between the frontal and temporal lobes, an economic decision will also depend on the emotional state of the individual. The upshot of this is that people in a good mood make optimistic judgments and choices, while the reverse happens in the state of a bad mood i.e., pessimistic judgments and choices.

Most of the existing papers on sporting events and stock price movements (see for example, Berument, Ceylan, and Gozpinar [2006]; Edmans, Garcia, and Norli [2007]; Kavetsos and Szymanski [2008]; Klein, Zwergel, and Heiden [2009]; Scholtens and Peenstra [2009]; Smith and Krige [2010]; Kaplanski and Levy, [2010a, 2010b]; Chen and Chen [2012]; Pantzalis and Park [2014]; Shu and Chang [2015]; Curatola, Donadelli, Kizys, and Riedel [2016]; Kaustia and Rantapuska [2016]; Akhigbe, Newman, and Whyte [2017]; Dimic, Neudl, Orlov, and Aijo [2018]) focus on the role of a multiple sporting event like the Olympics or soccer (football) matches, which is understandable, given the global reach of the sport. Comparatively, limited attention has been given to the role of cricket on stock market movements (barring a few notable exceptions like Edmans et al. [2007]; Mishra and Smyth [2010]; Abhijeet [2011]; Abidin and Azilawati [2011]; Verstoep, Singh, Nguyen, and Bhattacharya [2015]; Narayan, Rath, and Prabheesh [2016]), which is a bit surprising, given that it is second most popular sport with more than 2.5 billion fans around the world.

In this regard, the paper by Edmans et al. [2007] was the first to identify significant downward trend in local stock markets of countries, which suffered losses in cricket world cup matches. Inspired by this study, Mishra and Smyth [2010] examined the impact of the performance

\footnotetext{
${ }^{1}$ Michael A. Atherton is a broadcaster, journalist and a former England international first-class cricketer. And the above quote comes from one of his article on the importance of cricket in India, available at: https://www.thetimes.co.uk/article/games-soul-is-not-at-lords-it-is-here-7sq8510rd.
} 
of the Indian cricket team in One Day International (ODI) matches on stock returns. The paper showed that winning has no statistical significant upward movement while loss generates a significant downward movement in the stock market, with the effect being stronger when Sachin Tendulkar, India's most popular cricketer, plays and India loses. Abhijeet [2011] observed the reaction of two Indian stock indices (Sensex and Nifty) during the 2011 International Cricket Council (ICC) cricket world cup (held in India, Bangladesh and Sri Lanka) with respect to matches played by the Indian team. The author observed a positive upward trend in the markets when India won its matches, with the effect being even stronger when India won the final. However, Abidin and Azilawati [2011] could not detect an impact of cricket match results on the stock markets of Australia and New Zealand. Verstoep et al., [2015] examined the influence of the investors' sentiment on the stock market following performances by the national cricket teams of India and Australia. They found no evidence of impact on spot or futures stock prices emanating from the performances of key players or the overall team, detected a 'mood effect' of poor performance by key players of national cricket teams in reduced trading volumes on the following day. Narayan et al., [2016] concentrated on the stock market reaction to investor mood swings resulting from the Indian Premier League (IPL) cricket matches, which in turn involves participation of international professional cricket players from all across the world representing various franchises owned by major corporate houses. They found that stocks listed on the Bombay Stock Exchange (BSE) that sponsor the IPL cricket are unaffected by the cricket matches. Overall, the results seem to be mixed on the impact of cricket match results on stock returns, but one observation that seems to stand out is that the impact on stock prices following wins or losses are likely to be asymmetric in nature.

Given this, the objective of the study is to examine the behavioral impact in national sentiment generated by the feeling of optimism or pessimism following a win or defeat respectively of the Indian cricket team involved in One Day International (ODI) matches on movements in the national stock market. The choice of India as our case study is unsurprising, because one-day cricket especially, is the number one spectator-sport in the country, and hence, has also been predominantly studied by the majority of the cricket-related papers mentioned above. Also as of last data available in 2011, cricket stood at a US\$ 2.6 billion industry (Balasubramanian and Santhanam, [2011]), which is sure to have grown exponentially in the last few years due to massive corporate investment into the sport as a result of India's strong performance. In addition, currently, as of 2017, India also has a sizeable number of people, to the order of 3.23 crores, investing in the stock market (BSE, 2017).

However, unlike the existing studies, given that investor sentiment has been shown to have effects on higher moments of stock markets (Balcilar, Gupta, and Kyei [2018a], Balcilar, Demirer, Gupta, and Wohar [2018b]), we in this paper not only analyze the impact of India's performance in ODIs on stock return, but also on volatility. As discussed in the above-mentioned papers, investor sentiment tends to affect volatility of the market through the trading volume channel. In other words, investor sentiments, i.e., positive or negative moods following wins or losses, results in active or passive trading, which in turn, affects stock market volatility. It must be emphasized that the literature on the impact of trading volume changes due to informational flow on stock market volatility is based on the Mixture of Distribution Hypothesis (MDH) introduced by Clark (1973), or Sequential Information Arrival Hypothesis (SIAH) developed by Copeland (1976). The MDH postulates that daily price changes are driven by a set of information flow and the arrival of unexpected news is accompanied by the above average trading activity. On the other hand, the SIAH of Copeland (1976) questions the instantaneous relationship as predicted by MDH, and provides a different explanation. It argues that each trader observes the information signal 
differently at time and the information may not receive simultaneously, thereby generating a series of incomplete equilibria. Market equilibrium can be established provided that all traders receive same set of information simultaneously. Thus, the shift of new information is not immediate as considered in Clark (1973). Both MDH and SIAH believe that the price volatility of the market can be potentially predictable through the knowledge of trading volume, and that the relationship of volume and volatility is positive. However, we do not explore the impact of the impact of the Indian cricket team's performance in one-day international cricket matches on volumes here.

Note that financial market volatility is used as an important input in investment decisions, option pricing and financial market regulation (Poon and Granger, [2003]). In light of this, financial market participants care not only about the nature of volatility, but also about its level, with all traders making the distinction between good and bad volatilities (Caporin, Rossi, and Magistris [2016]). Good volatility is directional, persistent and relatively easy to predict, while, bad volatility is jumpy and comparatively difficult to foresee. Therefore, good volatility is generally associated with the continuous and persistent part, while bad volatility captures the discontinuous and jump component of volatility. Given this, it has been stressed that studying jumps can improve the overall understanding of the latent process of volatility (Gkillas, Gupta, and Wohar [2018; forthcoming]). In light of this, we too in our study incorporate the impact of ODI match results involving India on the predictability of various types of volatility jumps (small, big, good, and bad), besides return and realized volatility, as well as good and bad versions of the latter.

For our purpose, we use 5 minutes intraday data of the BSE (specifically the BSE200 index) covering the period of $30^{\text {th }}$ October 2006 to $31^{\text {st }}$ March 2017 to compute our daily return, realized volatility and volatility jumps (see Appendix A), the predictability of which in turn, are analyzed based on information derived from India's ODI performances, i.e., both wins and losses, to check for possible asymmetry. As far as the econometric framework goes, we rely on the nonparametric causality-in-quantiles test of Jeong, Hardle, and Song [2012] for our predictability analysis, and hence, in the process capture various phases of the stock market variables. Understandably, the causality-in-quantiles test used here is inherently a time-varying approach as various parts of the conditional distribution of return, realized volatility and volatility jumps would relate to various points in time associated with the evolution of these variables. The causality-in-quantiles approach has the following two main novelties: First, it is robust to misspecification errors as it detects the underlying dependence structure between the examined time series. This is particularly important as we show that our stock market variables are nonlinearly associated with the dummy variable capturing wins or losses. And second, using this methodology, we are able to test not only for nonlinear causality-in-mean (1st moment), but also for causality over the entire conditional distribution of the stock market variables, including the tails. This is again of tremendous value since our dependent variables, i.e., return, realized volatility and volatility jumps are shown to be non-normal. We present this procedure analytically in Appendix A, too.

To the best of our knowledge, this is the first paper to analyze the predictability of any sporting event, and in particular cricket, for equity return, volatility and jumps, based on a causality-in-quantiles approach. Note that, are analyzing the predictability or the lagged effect of completed cricket matches on stock market movements, based on the underlying theories of neuroeconomics, which tend to associate results of sport matches on investor sentiment and hence, the impact on stock market returns and volatility due to investment and trading volumes respectively. Our results show evidence of predictability from wins or losses for primarily volatility and jumps, with the impact on stock return being weak. 
The remainder of the paper is organized as follows: Section 2 presents the data used in this paper and discusses the empirical results. Section 3 provides a robustness analysis based on the stock market of Pakistan. Finally, Section 4 concludes the paper.

\section{Data and Empirical Results}

Based on the availability of intraday data on the Indian stock market, specifically the Bombay Stock Exchange's (BSE) index called the BSE200, our analysis covers the period of $30^{\text {th }}$ October 2006 to $31^{\text {st }}$ March 2017, i.e., daily 2577 observations (which corresponds to 263364 intraday 5-minutes price observations across all 2577 days). This index is a free float weighted index of 200 companies based on specified and non-specified lists of the BSE, and is selected on the basis of their market capitalization. It started as a cap-weighted index with a base value of 100, and base year 1989-90. The data on stock index is derived from Datastream of Thomson Reuters. At this stage it is important to emphasize that the choice of the BSE200 (instead of the BSE Sensex or the S\&P BSE 500) is primarily based on the availability of intraday data for this index, which in turn are required for us to compute our higher-moment statistics. Ideally, one should be using the data on the National Stock Exchange (NSE), as it is the largest stock exchange in India and accounts for more than $70 \%$ of the total market share. Even though the BSE has more firms listed on it compared to NSE, most of the firms listed on BSE are illiquid stocks, and NSE probably has more actively traded stocks than BSE. ${ }^{2}$ In other words, our index might not necessarily have the widest possible coverage, and hence given this, our analysis can be viewed as an initial attempt to study the higher-order impact of cricket match results on the Indian stock market.

We also define two dummy variables corresponding to wins and losses in the One Day International matches played by the Indian cricket team. The dummy win (loss) is designed to take the value of one (one) when India wins (loses) a match and zero otherwise, i.e., when they lose (win), there is no result following an abandonment, a tie, and also for stock market trading days when no matches are played. The dummies win $\left(D_{t}^{\text {win }}\right)$ and loss $\left(D_{t}^{\text {loss }}\right)$ are given respectively as follows:

$$
\begin{aligned}
D_{t}^{\text {win }} & = \begin{cases}1, & \text { win occured } \\
0, & \text { otherside }\end{cases} \\
D_{t}^{\text {loss }} & = \begin{cases}1, & \text { loss occured } \\
0, & \text { otherside }\end{cases}
\end{aligned}
$$

where $t$ is the specific day or date in the total number daily (2577) observations on which a match was either played or not played. . Also note that, following the extant literature on events occurring during weekends and financial markets (see, Balcilar, Gupta, Pierdzioch, Wohar [2018c] for a detailed discussion in this regard), for matches played during the weekend, we have moved them

\footnotetext{
${ }^{2}$ We would like to thank an anonymous referee for pointing this out to us. Given the concerns with the narrowness of the BSE200 index, we conducted some analysis based on the NSE index, with data on it again derived from Datastream. However, since intraday data is not available for the index, we used daily data, and applied the $k$-th order version of the causality in quantiles test developed by Balcilar et al., (2018d). This test allows us to check for causality in returns and volatility (captured by squared returns) within a nonparametric quantiles-based framework. But note that, without intraday data on the NSE, we cannot compute realized volatility and volatility jumps, and are only restricted to returns and squared returns, i.e., volatility. Based on this test, we found similar results to those obtained under the BSE. Specifically, we found that ODI match results affects the returns weakly and primarily at the upper quantiles, while strong impact on squared returns (volatility) is restricted at the lower end of the conditional distribution. Complete details of these results are available upon request from the authors.
} 
to the Friday that precedes the weekend. During the period of study, India played in 269 ODIs, won 159 of them, and lost 93, with 4 being tied and 13 having no results. The source of the data on cricket match information is: http://www.espncricinfo.com/. Table B1, reported in the Appendix B, summarizes the stock market related variables. As can be seen from the Jarque-Bera test of normality, all our stock market variables are non-normal - a results which provides preliminary motivation for using the quantiles-based method.

Now we are ready to analyze the results from our predictability exercise. Before we discuss the findings from the causality-in-quantiles test, for the sake of completeness and comparability, we first conducted the standard linear Granger causality test, with a lag-length of 1, as determined by the Schwarz Information Criterion (SIC). Note this implies that in our model day t's return is predicted by day $\mathrm{t}-1$ 's win or loss (standardized) ${ }^{3}$ dummy. The resulting $\chi^{2}(1)$ statistics obtained from the linear model applied on our various stock market metrics involving returns, realized volatility and jumps have been reported in Table 1 . As can be observed, there is no evidence of predictability in any of the cases (including returns as observed by some earlier studies), even at the 10 percent level of significance.

\section{[Table 1 about here.]}

Given this evidence of lack of predictability, and realizing the possibility that financial market variables are likely to be nonlinearly related with its predictors, we next statistically examine the presence of nonlinearity in the relationship between our stock market variables and the win and loss dummies separately. Nonlinearity, if present, would motivate the use of the nonparametric quantiles-in-causality approach, as the quantiles-based test would formally address nonlinearity in the relationship between the two variables under investigation. For this purpose, we apply the Brock, Dechert, Scheinkman, and LeBaron [1996, BDS] test on the residuals from the equations involving our various stock market metrics with one lag of the particular stock market variable under consideration and the win or loss dummy.

Table 2 presents the results of the BDS test of nonlinearity. As shown in this table, we find strong evidence, at highest level of significance, for the rejection of the null of i.i.d. residuals at various embedded dimensions $(m)$, which in turn, is indicative of nonlinearity in the relationship between our stock market variables and India's wins or losses. This finding of nonlinearity indicate that, the result of no-predictability based on the linear Granger causality tests, cannot be deemed robust and reliable.

[Table 2 about here.]

Given the strong evidence of nonlinearity in the relationship between our stock market variables and India's performance in ODI matches, we now turn our attention to the causality-in-quantiles test, which is robust to misspecification due to its nonparametric (i.e., data-driven) approach. As can be seen from Table 3, which reports this test for the quantile range of 0.05 to 0.95 , the null that win or loss does not Granger cause our stock market variables are quite similar in terms of the quantiles for which the null is rejected, but predictability is stronger under the loss dummy than under win. We can say this, since we normalized these dummies to have a standard deviation of one and hence, the strength of predictability is comparable. The above result tends to suggest that the optimism introduced by a win, is not as big in magnitude as pessimism following a loss. In

\footnotetext{
${ }^{3}$ The win and loss dummies were divided by their full-sample standard deviation, estimated or calculated based on the basic formula of standard deviation of a variable. By doing this, we removed the inherent variability of these dummies, and thus both of them have a standard deviation equal to 1 . This allows us to compare the strength of the impact of win or loss on the same dependent variable across the two dummies.
} 
general, predictability of return is the weakest, with the impact restricted to upper conditional quantiles, i.e., 0.80-0.90. For the other stock market variables predictability in general covers the lowest quantile $(0.05)$ to above the median with the exceptions of the extremely high quantiles or the highest quantile, with the exception of the large jumps, i.e., RVLJ. Another exception is the variable capturing the asymmetry in the jumps, i.e., RJA, for which predictability is centered around the median over the quantile range of 0.30 to 0.80 , and thus, excludes the extreme ends of the conditional distribution. In other words, this means that the India's performance in ODI matches does not affect extreme asymmetry defined by the difference between downside and upside jumps. $^{4}$

[Table 3 about here.]

In sum, India's ODI match performance seems to drive volatility more than return, with stronger effects observed under losses than wins, and also towards the lower end of the conditional distribution. In addition, the movements in volatility is primarily driven by the impact of wins or losses on volatility jumps (particularly large one, i.e., $R V L J$ ) - a result that motivates the decision to look beyond return and into volatility, and also the role of jumps in governing the latent process of volatility. However, by comparing the effects between wins and losses, the difference is not so strong. Hence, one can argue that India's ODI match performance does affect the "jumpy" part of the volatility process but, the effect is somehow similar between the optimism introduced by a win and the pessimism following a loss. Furthermore, the impact of ODI match results is observed to affect more the risk profile of the Indian stock market rather than the return, which in turn, could explain the conflicting results of the earlier studies dealing only with stock market return movements, and not looking at higher moment effects.

\section{Robustness}

To check for the robustness of our results, and also for the sake of comparability, we also conducted the same analyses for Pakistan, another nation, just like India, where cricket is the most important spectator-sport. The same sample period of 30th October, 2006 to 31st March 2017 is considered, giving us a total of 2581 trading days for the Karachi Stock Exchange (KSE), where we look at specifically the movements in KSE100 index. During this period, Pakistan played in 217 ODIs, won 109 of them, and lost 102, with 2 being tied and 4 having no results. The sources for the stock market and the cricket related data are the same as that for India.

The results have been reported in Table B2 of the Appendix. While results are in general similar to those of India, in the sense that volatility movements are primarily driven by jumps, the stark difference that is observed comes from the stock market return. In case of Pakistan, results of ODI matches do tend to predict the entire conditional distribution of the return. So unlike India, for Pakistan, the impact is stronger on return, than on the risk profile, in terms of the coverage of predictability over the respective conditional distributions. This could be because of the relatively stronger influence of large jumps in the BSE200 driving the volatility process than compared to the KSE100 where the win or losses does not impact bad volatility ( $\left.\mathrm{RS}^{-}\right)$, i.e., in case of India, results of matches have sudden large changes than consistent impact throughout the trading hour.

\footnotetext{
${ }^{4}$ By construction the values of RJA is equal zero or almost equal to zero in its lower quantiles i.e., 0.05 to 0.20 . Thus, it is expected that the impact of India's performance in ODI matches on RJA in lower quantiles to be statistically significant equal to zero. This happens due to the fact that there is no asymmetry between downside and upside jumps.
} 


\section{Conclusion}

The objective of the study is to examine the behavioral impact in national sentiment generated by the feeling of optimism or pessimism following a win or defeat respectively of the Indian cricket team involved in ODI matches on movements in the national stock market. While analyzing the stock market impacts, we go beyond the existing literature in not only concentrating on return, but also volatility and volatility jumps. For our purpose, we use 5 minutes intraday data of the BSE200 index covering the period of 30th October 2006 to 31st March 2017 to compute our daily return, realized volatility and volatility jumps, the predictability of which in turn, are analyzed based on information derived from India's ODI performances, i.e., both wins and losses. In terms of the econometric framework goes, we rely on the nonparametric causality-in-quantiles test of Jeong et al. [2012] for our predictability analysis, which in turn, is robust to misspecification due to nonlinearity, being a data-driven procedure.

Starting off with the standard linear causality test, we were unable to detect any evidence of India's ODI match performances causing return, volatility or jumps. But, we indicate that linear Granger causality test results cannot be relied upon because formal tests reveal strong evidence of nonlinearity between the stock market variables and the measure of investor mood, i.e., wins or losses. Hence, linear Granger causality tests are mis-specified. When we use the nonparametric causality-in-quantiles test instead, we were able to detect evidence rejecting the null hypothesis that wins or loses does not Granger cause volatility and jumps, especially over the lower-quantiles of the conditional distributions, with losses having stronger predictability than wins. The impact on stock return is, however, weak and restricted towards the upper end of the conditional distribution. Thus, our results indicated that when we control for misspecification due to nonlinearity, it is indeed true that wins or losses of the Indian cricket team in ODI matches can predict movements in volatility and volatility jumps. In sum, recalling the importance of jumps in the volatility process, our results tend to suggest that the channel through which results of ODI matches affect low to moderately high (conditional) volatility, is primarily through (large) jumps. In other words, we add an additional layer of information in the sense that results of ODI matches causes sudden fluctuations in trading volumes, which in turn affects the large jump process, and then in turn impacts on volatility.

Our results have important implications for decisions of investors, in the sense that results of ODI matches, in particular losses, would tend to impact the risk profile of the Indian equity market, with the predictability emanating from primarily large non-diversifiable risks (i.e., large jumps). In other words, cricket match results of the Indian team can be utilized to predict market or systematic risk, i.e., uncertainty, and would allow for accurate pricing of securities by proving ahead of time information on the risk-premium. Understandably, if investors are aiming control for such systematic risks, they need to devise appropriate hedging strategies. But, we highlight that for the investors to do so, they must be relying on a nonparametric framework, which is also capable of producing quantile-specific results, rather than a linear model, since the data-driven approach used by us in this paper not only controls for nonlinearity, but also studies the various phases of returns, volatility and jumps, via the quantiles. Usage of a linear model would tend to suggest that results of cricket matches in India does not impact the equity market movements, and hence, the market is efficient in the semi-strong sense, which in fact is not the case when we allow for a regime-based nonlinear model.

Currently, our analysis looks at the leading role of completed matches on the equity market movements, as part of future research, given that we have available intraday data, it would be interesting to track the behavior of the market when a match is actually in progress. In this regard, 
we would need to study a set of important matches on a specific number of days, rather than the long-sample of daily data used in this paper. Finally, given that the existing literature has identified that the investors' behavior can be measured by the transaction volume, future research may explore the impact of the Indian cricket team's performance in one-day international cricket matches on volumes. Such analysis can also be extended to other teams and markets. 


\section{References}

Abhijeet, C. (2011). Cricket World Cup and Indian Stock Market: Is there any relationship? Behavioral Finance

Research: https://behavioralfinance.wordpress.com/2011/03/25/cricket-world-cup-and-indian-stockmarket-is-there-any-relationship/.

Abidin, S., and Azilawati, B. (2011). Impact of International Sports Results on Stock Returns: Evidence from Australia and New Zealand. World Business and Economics Research Conference.

Akhigbe, A., Newman, M., and Whyte, A. M. (2017). Predictable Sports Sentiment and Local Trading. Financial Management, 46(2), 433-453.

Andersen, T. G., Dobrev, D., and Schaumburg, E. (2012). Jump-robust volatility estimation using nearest neighbor truncation. Journal of Econometrics, 169(1), 75-93.

Baker, M., and Wurgler, J. (2006). Investor sentiment and the cross-section of stock returns. Journal of Finance, 61, 1645-1680

Balasubramanian, S., and Santhanam, V. (2011). The Business of Cricket: The Story of Sports Marketing in India. Harper Collins, New York, USA.

Balcilar, M. Gupta, R., and Kyei, C. (2018a). Predicting stock returns and volatility with investor sentiment indices: a reconsideration using a nonparametric causality-in-quantiles test. Bulletin of Economic Research, 70(1), 74-87.

Balcilar, M., Demirer, R., Gupta, R., and Wohar, M.E. (2018b). Differences of opinion and stock market volatility: evidence from a nonparametric causality-in-quantiles approach. Journal of Economics and Finance, 42(2), 339-351.

Balcilar, M., Gupta R., Nguyen D.K., and Wohar, M.E. (2018d). Causal effects of the United States and Japan on Pacific-Rim stock markets: nonparametric quantile causality approach. Applied Economics, 50(53), 5712-5727.

Balcilar, M., Gupta, R., Pierdzioch, C., and Wohar, M.E. (2018c). Terror attacks and stock-market fluctuations: evidence based on a nonparametric causality-in-quantiles test for the G7 countries. The European Journal of Finance, 24(4), 333-346.

Barndorff-Nielsen, O.E., and Shephard, N. (2006). Econometrics of testing for jumps in financial economics using bipower variation. Journal of Financial Economics, 4, 1-30.

Barndorff-Nielsen, O.E., and Shephard, N. (2010). Volatility and time series econometrics: Essays in honor of robert f.engle, chapter measuring downside risk-realised semivariance.

Bekaert, G., and Hoerova, M. (2014). The VIX, the variance premium and stock market volatility. Journal of Econometrics, 183(2), 181-192.

Berument, H., Ceylan, N. B., and Gozpinar, E. (2006). Performance of soccer on the stock market: Evidence from Turkey. The Social Science Journal, 43(4), 695-699.

Bollerslev, T., and Li, S. Z. and Zhao, B. (2018). Good Volatility, Bad Volatility and the CrossSection of Stock Returns Journal of Financial and Quantitative Analysis (JFQA), Forthcoming. 
Brock, W., Dechert, D., Scheinkman, J., and LeBaron, B. (1996). A test for independence based on the correlation dimension. Econometric Reviews, 15, 197-235.

Caporin, M., Rossi, E., and Santucci de Magistris, P. (2016). Volatility jumps and their economic determinants. Journal of Financial Econometrics, 14(1), 29-80.

Chen, C. D., and Chen, C. C. (2012). Assessing the Effects of Sports Marketing on Stock Returns: Evidence From the Nippon Professional Baseball Series. Journal of Sports Economics, 13(2), 169-197.

Christensen, K., Oomen, R.C., and Podolskij, M. (2010). Realized quantile-based estimation of the integrated variance. Journal of Econometrics, 159 (1), 74-98.

Clark, P. (1973). A Subordinated Stochastic Process Model with Finite Variances for Speculative prices. Econometrica, Vol. 41(1), 135-155.

Copeland, T. E. (1976). A Model for Asset Trading under the Assumption of Sequential Information Arrival. Journal of Finance, 31(4), 1149-1168.

Corsi, F., Pirino, D., and Reno, R. (2010). Threshold bipower variation and the impact of jumps on volatility forecasting. Journal of Econometrics, 159(2), 276-288

Curatola, G., Donadelli, M., Kizys, R., and Riedel, M. (2016). Investor Sentiment and Sectoral Stock Returns: Evidence from World Cup Games. Finance Research Letters, 17, 267-274.

Dimic, N., Neudl, M., Orlov, V., and Aijo, J. (2018). Investor sentiment, soccer games and stock returns. Research in International Business and Finance, 43, 90-98.

Duong, D., and Swanson, N. R. (2011). Volatility in discrete and continuous-time models: A survey with new evidence on large and small jumps. In Missing Data Methods: TimeSeries Methods and Applications (pp. 179-233). Emerald Group Publishing Limited.

Duong, D., and Swanson, N. R. (2015). Empirical evidence on the importance of aggregation, asymmetry, and jumps for volatility prediction. Journal of Econometrics, 187(2), 606-621.

Edmans, A., Garcia, D., and Norli, O. (2007). Sports sentiment and stock returns. Journal of Finance, 62(4), 1967-1998.

Fan, Y., and Li, Q. (1999). Central limit theorem for degenerate U-statistics of absolutely regular processes with applications to model specification testing. Journal of Nonparametric Statistics, 10(3), 245-271.

Gkillas, K., Gupta, R., and Wohar, M.E. (2018). Volatility jumps: The role of geopolitical risks. Finance Research Letters, 27, 247-258.

Gkillas, K., Gupta, R., and Wohar, M.E. (Forthcoming). Oil Shocks and Volatility Jumps. Review of Quantitative Finance and Accounting.

Huang, D., Jiang, F., Tu, J., and Zhou, G. (2015). Investor sentiment aligned: A powerful predictor of stock returns. Review of Financial Studies, 28, 791-837.

Jeong, K., Härdle, W.K., and Song, S. (2012). A consistent nonparametric test for causality in quantile. Economic Theory, 28, 861-887.

Jiang, F., Lee, J., Martin, X., and Zhou, G. (2018). Manager Sentiment and Stock Returns. Journal of Financial Economics. 
Kaplanski, G., and Levy, H. (2010a). Exploitable predictable irrationality: The FIFA World Cup effect on the US stock market. Journal of Financial and Quantitative Analysis, 45(2), 535553.

Kaplanski, G., and Levy, H. (2010b). Sentiment and stock prices: The case of aviation disasters. Journal of Financial Economics, 95(2), 174-201.

Kaustia, M., and Rantapuska, E. (2016). Does mood affect trading behavior? Journal of Financial Markets, 29, 1-26.

Kavetsos, G., and Szymanski, S. (2008). Olympic games, terrorism and their impact on the London and Paris stock exchanges. Revue D Economie Politique, 118(2), 189-206.

Klein, C., Zwergel, B., and Heiden, S. (2009). On the existence of sports sentiment: The relation between football match results and stock index returns in Europe. Review of managerial science, 3(3), 191-208.

Li, Q. (1999). Consistent model specification tests for time series econometric models. Journal of Econometrics, 92(1), 101-147.

Mancini, C. (2009). Non-parametric threshold estimation for models with stochastic diffusion coefficient and jumps. Scandinavian Journal of Statistics, 36 (2), 270-296.

Mishra, V., and Smyth, R. (2010). An examination of the impact of India's performance in oneday cricket internationals on the Indian stock market. Pacific-Basin Finance Journal, 18(3), 319-334.

Narayan, P. K., Rath, B. N., and Prabheesh, K. P. (2016). What is the value of corporate sponsorship in sports? Emerging Markets Review, 26, 20-33.

Pantzalis, C., and Park, J. C. (2014). Exuberance out of left field: Do sports results cause investors to take their eyes off the ball? Journal of Economic Behavior and Organization, 107, 760780 .

Poon, S-H, and Granger, C. W. J. (2003). Forecasting Volatility in Financial Markets: A Review. Journal of Economic Literature, 41(2), 478-539.

Scholtens, B., and Peenstra, W. (2009). Scoring on the stock exchange? The effect of football matches on stock market returns: an event study. Applied Economics, 41(25), 3231-3237.

Shu, H. C., and Chang, J. H. (2015). Investor Sentiment and Financial Market Volatility. Journal of Behavioral Finance, 16(3), 206-219.

Smith, B. K., and Krige, J. D. (2010). Evaluating the economic impact of national sporting performance: Evidence from the Johannesburg Stock Exchange. South African Journal of Business Management, 41(3), 1-11.

Verstoep, A., Singh, H., Nguyen, A., and Bhattacharya, S. (2015). Short-term impacts of the cricket match performances on national share markets - a case study of India and Australia. Sport in Society, 18(3), 263-274.

Zhou, G. (2018). Measuring Investor Sentiment. Annual Review of Financial Economics, 10, 239259. 
Table 1: Linear Granger Causality

\begin{tabular}{|c|c|c|c|}
\hline Dependent variable & Independent variable & $\chi^{2}(1)$-statistic & $p$-value \\
\hline \multirow[b]{2}{*}{$r$} & Win & 0.0126 & 0.9105 \\
\hline & Loss & 1.3391 & 0.2473 \\
\hline \multirow{2}{*}{$R V$} & Win & 0.0041 & 0.9492 \\
\hline & Loss & 0.0012 & 0.9723 \\
\hline \multirow{2}{*}{$R J$} & Win & 0.0038 & 0.9507 \\
\hline & Loss & 0.2147 & 0.6431 \\
\hline \multirow{2}{*}{$R S^{-}$} & Win & 0.7281 & 0.3936 \\
\hline & Loss & 0.0525 & 0.8188 \\
\hline \multirow[b]{2}{*}{$R S^{+}$} & Win & 0.0661 & 0.7971 \\
\hline & Loss & 1.1233 & 0.2893 \\
\hline \multirow{2}{*}{$R J^{-}$} & Win & 0.0236 & 0.8778 \\
\hline & Loss & 0.0645 & 0.7996 \\
\hline \multirow{2}{*}{$R J^{+}$} & Win & 0.0025 & 0.9601 \\
\hline & Loss & 0.0013 & 0.9713 \\
\hline \multirow{2}{*}{$R J A$} & Win & 0.0279 & 0.8673 \\
\hline & Loss & 0.0818 & 0.7749 \\
\hline \multirow{2}{*}{$R V L J$} & Win & 0.0478 & 0.8269 \\
\hline & Loss & 0.1081 & 0.7423 \\
\hline \multirow{2}{*}{$R V S J$} & Win & 0.4455 & 0.5045 \\
\hline & Loss & 0.0054 & 0.9413 \\
\hline
\end{tabular}

Note: The null hypothesis is that Win or Loss does not Granger cause the stock market variables, where, $r, R V, R J$, $R S^{-}, R S^{+}, R J^{-}, R J^{+}, R J A, R V L J, R V S J$ stands for return, realized volatility, volatility jump, bad volatility, good volatility, bad jumps, good jumps, asymmetric jumps, large jumps and small jumps respectively. 
Table 2: BDS Test of Nonlinearity

\begin{tabular}{|c|c|c|c|c|c|c|}
\hline \multirow{2}{*}{$\begin{array}{c}\text { Dependent } \\
\text { variable }\end{array}$} & $\begin{array}{c}\text { Independent } \\
\text { variable }\end{array}$ & \multicolumn{5}{|c|}{ Dimension } \\
\cline { 2 - 7 }$r$ & Win & $11.558^{* * *}$ & $15.718 * * *$ & $18.714 * * *$ & $21.477 * * *$ & $23.856 * * *$ \\
\cline { 2 - 7 } & Loss & $11.546 * * *$ & $15.715 * * *$ & $18.703 * * *$ & $21.460 * * *$ & $23.840 * * *$ \\
\hline \multirow{2}{*}{$R V$} & Win & $24.832 * * *$ & $29.719 * * *$ & $33.348 * * *$ & $36.779 * * *$ & $40.548 * * *$ \\
\cline { 2 - 7 } & Loss & $24.825 * * *$ & $29.713 * * *$ & $33.342 * * *$ & $36.772 * * *$ & $40.537 * * *$ \\
\hline \multirow{2}{*}{$R J$} & Win & $4.796 * * *$ & $5.823 * * *$ & $6.925 * * *$ & $7.580 * * *$ & $7.721 * * *$ \\
\cline { 2 - 7 } & Loss & $4.654 * * *$ & $5.660 * * *$ & $6.710 * * *$ & $7.344 * * *$ & $7.611 * * *$ \\
\hline \multirow{2}{*}{$R S^{-}$} & Win & $26.764 * * *$ & $31.654 * * *$ & $34.903 * * *$ & $38.370 * * *$ & $42.220 * * *$ \\
\cline { 2 - 7 } & Loss & $27.190 * * *$ & $31.830 * * *$ & $34.951 * * *$ & $38.240 * * *$ & $41.986 * * *$ \\
\hline \multirow{2}{*}{$R S^{+}$} & Win & $28.958 * * *$ & $33.328 * * *$ & $36.954 * * *$ & $40.705 * * *$ & $45.237 * * *$ \\
\cline { 2 - 7 } & Loss & $28.803 * * *$ & $33.142 * * *$ & $36.855 * * *$ & $40.620 * * *$ & $45.129 * * *$ \\
\hline \multirow{2}{*}{$R J^{-}$} & Win & $8.009 * * *$ & $9.821 * * *$ & $11.217 * * *$ & $12.574 * * *$ & $13.787 * * *$ \\
\cline { 2 - 7 } & Loss & $8.640 * * *$ & $9.963 * * *$ & $11.537 * * *$ & $12.913 * * *$ & $14.209 * * *$ \\
\hline \multirow{2}{*}{$R J^{+}$} & Win & $8.092 * * *$ & $9.504 * * *$ & $10.967 * * *$ & $12.554 * * *$ & $14.064 * * *$ \\
\cline { 2 - 7 } & Loss & $8.290 * * *$ & $9.636 * * *$ & $11.085 * * *$ & $12.642 * * *$ & $14.099 * * *$ \\
\hline \multirow{2}{*}{$R J A$} & Win & $1.825 *$ & $4.732 * * *$ & $6.884 * * *$ & $8.344 * * *$ & $9.049 * * *$ \\
\cline { 2 - 7 } & Loss & $1.707 *$ & $4.312 * * *$ & $6.423 * * *$ & $7.881 * * *$ & $8.578 * * *$ \\
\hline \multirow{2}{*}{$R V L J$} & Win & $10.782 * * *$ & $12.739 * * *$ & $14.553 * * *$ & $16.458 * * *$ & $18.411 * * *$ \\
\cline { 2 - 7 } & Loss & $10.739 * * *$ & $12.682 * * *$ & $14.493 * * *$ & $16.392 * * *$ & $18.352 * * *$ \\
\hline \multirow{2}{*}{$R V S J$} & Win & $11.014 * * *$ & $12.593 * * *$ & $13.710 * * *$ & $14.955 * * *$ & $16.425 * * *$ \\
\cline { 2 - 7 } & Loss & $11.049 * * *$ & $12.647 * * *$ & $13.780 * * *$ & $15.032 * * *$ & $16.516 * * *$ \\
\hline
\end{tabular}

Note: See Notes to Table 1. Entries correspond to the $z$-statistic of the BDS test with the null of i.i.d. residuals, with the test applied to the residuals recovered from the equation involving the various stock market variables with one lags each of the stock market variable under consideration and Win or Loss; *** (*) indicates rejection of the null hypothesis at 1 (10) percent level of significance. 
Table 3. Causality-in-Quantiles Results for the Stock Market of India

\begin{tabular}{|c|c|c|c|c|c|c|c|c|c|c|c|c|}
\hline \multirow{2}{*}{$\begin{array}{l}\text { Dependent } \\
\text { variable }\end{array}$} & \multirow{2}{*}{$\begin{array}{l}\text { Independent } \\
\text { variable }\end{array}$} & \multicolumn{11}{|c|}{ Quantile } \\
\hline & & 0.05 & 0.10 & 0.20 & 0.30 & 0.40 & 0.50 & 0.60 & 0.70 & 0.80 & 0.90 & 0.95 \\
\hline \multirow{2}{*}{$r$} & Win & 0.69 & 0.92 & 0.60 & 0.50 & 0.83 & $1.83 *$ & 1.24 & 1.57 & $2.13^{* *}$ & $2.70 * * *$ & $1.90 *$ \\
\hline & Loss & 0.71 & 0.90 & 0.75 & 0.68 & 0.88 & 1.64 & 1.13 & 1.38 & $2.20 * *$ & $2.70 * * *$ & $2.04 * *$ \\
\hline \multirow{2}{*}{$R V$} & Win & $2.96 * * *$ & $6.93 * * *$ & $4.50 * * *$ & $3.27 * * *$ & $2.63 * * *$ & $2.57 * * *$ & 1.60 & 1.11 & 0.71 & 0.45 & 0.48 \\
\hline & Loss & $2.84 * * *$ & $6.77 * * *$ & $4.99 * * *$ & $3.56^{* * *}$ & $2.70 * * *$ & $2.50 * *$ & $1.68^{*}$ & 1.18 & 0.79 & 0.53 & 0.57 \\
\hline \multirow{2}{*}{$R J$} & Win & $1619.95^{* * *}$ & $955.88 * * *$ & $446.35 * * *$ & $211.54 * * *$ & $82.37 * * *$ & $16.62 * * *$ & 0.43 & 0.52 & 0.41 & 0.27 & 0.31 \\
\hline & Loss & $1699.12 * * *$ & $1004.61 * * *$ & $472.21 * * *$ & $226.42 * * *$ & $90.33^{* * *}$ & $19.70 * * *$ & 0.60 & 0.62 & 0.43 & 0.33 & 0.39 \\
\hline \multirow{2}{*}{$R S^{-}$} & Win & $3.71 * * *$ & $9.70 * * *$ & $16.34 * * *$ & $20.77 * * *$ & $24.17 * * *$ & $26.18 * * *$ & $18.28 * * *$ & $8.78^{* * *}$ & $4.43 * * *$ & 0.22 & 0.15 \\
\hline & Loss & $3.15 * * *$ & $9.63 * * *$ & $17.26^{* * *}$ & $21.38 * * *$ & $25.34 * * *$ & $26.78 * * *$ & $18.45 * * *$ & $8.71 * * *$ & $4.98 * * *$ & 0.43 & 0.35 \\
\hline \multirow{2}{*}{$R S^{+}$} & Win & $4.51 * * *$ & $13.70 * * *$ & $22.43^{* * *}$ & $19.99 * * *$ & $13.89 * * *$ & $7.20 * * *$ & $6.95 * * *$ & $4.61 * * *$ & $2.08 * *$ & 1.56 & 1.31 \\
\hline & Loss & $4.84 * * *$ & $14.22 * * *$ & $22.96 * * *$ & $21.22 * * *$ & $14.85^{* * *}$ & $8.16^{* * *}$ & $7.50 * * *$ & $4.82 * * *$ & $2.28 * *$ & $1.86^{*}$ & 1.45 \\
\hline \multirow{2}{*}{$R J^{-}$} & Win & $2191.00^{* * *}$ & $1304.54 * * *$ & $612.04 * * *$ & $289.16^{* * *}$ & $111.07 * * *$ & $21.04 * * *$ & 0.02 & 0.02 & 0.03 & 0.04 & 0.01 \\
\hline & Loss & $2292.88^{* * *}$ & $1368.07 * * *$ & $645.57 * * *$ & $308.03 * * *$ & $120.81 * * *$ & $24.59 * * *$ & 0.04 & 0.05 & 0.07 & 0.05 & 0.06 \\
\hline \multirow{2}{*}{$R J^{+}$} & Win & $1943.44 * * *$ & $1147.28 * * *$ & $533.74 * * *$ & $250.77 * * *$ & $95.73 * * *$ & $17.88 * * *$ & 0.23 & 1.09 & 0.93 & 0.79 & 0.36 \\
\hline & Loss & $2031.82 * * *$ & $1201.89 * * *$ & $562.25 * * *$ & $266.67 * * *$ & $103.84 * * *$ & $20.82 * * *$ & 0.39 & 1.33 & 1.02 & 0.89 & 0.35 \\
\hline \multirow{2}{*}{$R J A$} & Win & 0.00 & 0.00 & 0.00 & $1087.67 * * *$ & $665.66 * * *$ & $380.40 * * *$ & $185.17 * * *$ & $60.32 * * *$ & $2.45^{* *}$ & 0.00 & 0.00 \\
\hline & Loss & 0.00 & 0.00 & 0.00 & $1087.91 * * *$ & $665.85 * * *$ & $380.54 * * *$ & $185.27 * * *$ & $60.37 * * *$ & $2.47 * *$ & 0.00 & 0.00 \\
\hline \multirow{2}{*}{$R V L J$} & Win & $1446.13^{* * *}$ & $858.74 * * *$ & $406.19 * * *$ & $196.05 * * *$ & $79.12 * * *$ & $17.95 * * *$ & 0.86 & $1.92 *$ & $6.55 * * *$ & $4.87 * * *$ & $1.70 *$ \\
\hline & Loss & $1509.14 * * *$ & $897.67 * * *$ & $426.88 * * *$ & $207.96^{* * *}$ & $85.52 * * *$ & $20.56^{* * *}$ & 1.23 & $1.70^{*}$ & $6.55 * * *$ & $4.75 * * *$ & $1.84 *$ \\
\hline \multirow{2}{*}{$R V S J$} & Win & $2323.11 * * *$ & $1389.25 * * *$ & $664.92 * * *$ & $326.26 * * *$ & $135.79 * * *$ & $33.45 * * *$ & 0.05 & 0.05 & 0.07 & 0.07 & 0.03 \\
\hline & Loss & $2419.66^{* * *}$ & $1451.22 * * *$ & $698.39 * * *$ & $345.52 * * *$ & $146.13 * * *$ & $37.73 * * *$ & 0.16 & 0.08 & 0.11 & 0.13 & 0.08 \\
\hline
\end{tabular}

Note: See Notes to Table 1; DV (IV) stands for dependent variable (independent variable); The entries correspond to the standard normal $\hat{J}_{T}$ statistic which tests whether Win or Loss Granger causes the various stock market variables at a specific quantile. ${ }^{* * * * *},{ }^{*}$ indicates rejection of the null hypothesis of no-causality at 1 , 5 and $10 \%$ levels of significance respectively., with corresponding critical values of 2.575, 1.96 and 1.645. 


\section{Appendix A. Methodology}

\section{A.1. Volatility jumps}

\section{A.1.1. Intraday returns}

This appendix provides a brief description of the estimation of various types of volatility jumps from intraday returns. We observe the price process in days $t$, consisting of $N+1$ intraday prices or $N$ intraday returns, after removing one observation. Assuming that the number of intraday observations per day is constant across all days, the returns during such intraday time periods cover $t_{0}<t_{1}<\cdots<t_{N+1}$. In our study, we excluded from the analysis the days with low variability resulting due to limited liquidity. ${ }^{5}$ However, there are few such intraday patterns in our sample, and are mainly during the early part of the sample. Generally, the indices under consideration reasonably a satisfactory liquidity with a continuous trading history. Hence, the majority of intraday observations are employed in our dataset, giving us a total of 2577 daily observations. Note that on days that were removed due to low liquidity, there were no matches played on that date. Then, we construct intraday returns as the logarithmic difference between two consecutively observed prices (5-minute by 5-minute), within a day, as:

$$
r_{t, i}=\log \left(p_{t, i}\right)-\log \left(p_{t, i-1}\right)
$$

where $r_{t, i}$ is intraday returns and $p_{i, t}$ accounts for the intraday price in 5-minutes $i$ and $i=$ $(1, \ldots, N)$, where $N$ is the total number of intraday observations within a day $t$.

\section{A.1.2. Realized Variance and Volatility Jumps}

Market volatility (henceforth volatility) as a measure of risk induces uncertainty in investment decisions and thus, is a keystone for asset management decision making and portfolio risk management. In the existing literature, there is evidence that the volatility of a price process has jumpy behaviour and thus can be latent. This jumpy behaviour adds an extra source of nondiversifiable risk, which is locally sourced making the prediction more difficult.

In the existing literature, the terms "good" and "bad" volatility are quite common and have been widely used to describe different market phases such as booms or crashes. Caporin, Rossi, and Magistris [2016] used the term good volatility as the directional, persistent and relatively easy to predict part of volatility, while, with term bad referred to the jumpy part which is comparatively difficult to foresee. Bollerslev, Li and Zhao [2018], in a realized estimation framework, differentiate between "good" and "bad" volatility and used the corresponding realized up and down semi-variance measures for this distinction. In a trading day, the realized up term is defined by the variability of upside movements of the price process constructed only from positive intraday returns, while the down term corresponds to the variability of downside movements constructed by negative intraday returns. In this vein, we can easily understand that causes associated with bad or good news can affect the price process in a different way which they can be captured from the upside and downside part. Moreover, depending on the importance of a new, its effect can cause a large jump in the market, which always constitutes a source of additional anxiety to market participants.

\footnotetext{
${ }^{5}$ Days with recorded prices for less than 30 percent of the expected observations on operating time of the initial sample are removed from the sample.
} 
In light of this, we study the impact of ODI match results associated with bad (losses) or good (win) news involving India on the predictability of various types of volatility jumps (small, large, good, and bad), besides return and realized volatility, as well as good and bad versions of the latter. In this way, we take into account both different views different views of volatility, associated with the bad and good distinction, providing empirical findings not only for its nature but also for its level.

We assume the dynamics for the $\log$-price $p_{t}$ of an asset follows a general stochastic volatility jump-diffusion model:

$$
d p_{t}=\mu_{t} d t+\sigma_{t} d W_{t}+\kappa_{t} d q_{t}
$$

where $\mu_{t}$ stands for the drift term with a continuous variation sample path, $\sigma_{t}$ stands for the stochastic volatility process, which is a strictly positive, $W_{t}$ stands for the driving standard Brownian motion and last part, $\kappa_{t} d q_{t}$, is associated with jumpy part of volatility represents the random jump size, while $0 \leq t \leq T$.

For discrete prices process, the volatility at the given day $t$ includes jump variation, consequently it cannot be considered as an unbiased estimator of integrated volatility. A daily point estimate of can be estimated by the quadratic variation as follows:

$$
Q V_{t}=\int_{t-1}^{t} \sigma_{s}^{2} d s+\sum_{t-1<s \leq t} \kappa_{s}^{2} t
$$

where the $\int_{t-1}^{t} \sigma_{s}^{2} d s$ denotes the its continuous variation, while the $\sum_{t-1<s \leq t} \kappa_{s}^{2} t$ denotes the jump variation in $[t-1, t]$.

In this paper, we employ all remain intraday returns to estimate daily realized volatility. For each day $t$, we retrieve a daily point estimate of the $R V_{t}$ obtained from intraday returns. The daily realized volatility is constructed by summing up all successive intraday squared returns, as follows:

$$
R V_{t} \equiv \sum_{i=1}^{N} r_{t, i}^{2}
$$

where $R V_{t}$ is a benchmark realized volatility estimator, $r_{t, i}$ represents the 5-minute return $i$ within a day $t$ and $i=(1, \ldots, N)$, where $N$ is the total number of intraday observations within a day $t$. Under weak regularity conditions and as $N \rightarrow \infty$, the realized volatility $R V_{t}$ is a consistent estimator of quadratic variation $Q V_{t}$ which is regarded as the best estimator of integrated (latent) volatility:

$$
R V_{t} \stackrel{N \rightarrow \infty}{\longrightarrow} Q V_{t}=\int_{t-1}^{t} \sigma_{s}^{2} d s+\sum_{t-1<s \leq t} \kappa_{s}^{2} t
$$

where the $Q V_{t}$ is separated into its continuous and jump components, where $\int_{t-1}^{t} \sigma_{s}^{2} d s$ refers to its continuous variation and $\sum_{t-1<s \leq t} \kappa_{s}^{2} t$ refers to the jump variation.

To separate the price increments into jumps and continuous price moves it is needed to estimate the part of the total variation due to continuous price moves (also called daily integrated variance), while the total variation can be estimated by the realized variation. The jump variation can be defined as the difference between the realized and continuous variation. In the existing literature, there are several estimators of the total variation due to continuous price (jump-robust) moves. For example, the study of Barndorff-Nielsen and Shephard [2006] was one of the first contributors in this regard who proposed the bipower variation, with Mancini [2009] suggesting the threshold realized variance. Christensen, Oomen, and Podolskij [2010] developed the quantilebased realized variance and Andersen, Dobrev, and Schaumburg [2012]'s work deals with the "nearest neighbor truncation" estimators.

In this paper, following Bekaert and Hoerova [2014], we employ the threshold bipower variation $\left(T B P V_{t}\right)$ to estimate continuous sample path variation $\int_{t-1}^{t} \sigma_{s}^{2} d s$, as defined in Corsi, 
Pirino, and Reno [2010]. The threshold bipower variation substantially reduces the small-sample bias that the standard bipower variation estimates may exhibit. The $T B P V_{t}$ is defined as follows:

$$
T B P V_{t}=\xi_{1}^{-2} \sum_{i=2}^{N}\left|r_{t, i-1}\right| \cdot\left|r_{t, i}\right| \cdot I_{\left\{\left|r_{t, i-1}\right|^{2} \leq \theta_{i-1}\right\}} \cdot I_{\left\{\left|r_{t, i}\right|^{2} \leq \theta_{i}\right\}}
$$

where $I_{\{\cdot\}}$ is the indicator function corresponding the threshold function $r_{t, i}$ stands for the 5-minute returns series and $\xi_{r}=E\left(|Z|^{r}\right), Z \sim N(0,1)$ and $r>0$. For example, when $r=1, \xi_{1}=\sqrt{2 / \pi}$. The parameter $\theta$ is dependent on the local spot variance $\theta_{t}$ which is equal to $c_{\theta}^{2} \widehat{V}_{t}$, where $c_{\theta}^{2}$ is a scalefree constant. The $c_{\theta}^{2}$ can be used to change the threshold, or by changing it can be used as a robustness test of the estimates regarding the choice of the threshold. The $\widehat{V}_{t}$ stands for local variance, which is am auxiliary estimator of $\sigma_{t}^{2}$. The $\widehat{V}_{t}$ is estimated with a non-parametric filter via a range estimate from the data within the neighborhood. ${ }^{6}$

Then, we estimate the jump statistic $\left(Z J_{t}^{(T B P V)}\right)$, following Duong and Swanson [2015], as follows:

$$
Z J_{t}^{(T B P V)}=\sqrt{N} \cdot \frac{\left(R V_{t}-T B P V_{t}\right) \cdot R V_{t}^{-1}}{\left[\left(\xi_{1}^{-4}+2 \xi_{1}^{-2}-5\right) \max \left\{1, T Q_{t} \cdot T B P V_{t}^{-2}\right\}\right]^{1 / 2}} \rightarrow N(0,1)
$$

where $T Q_{t}$ stands for the realized tri-power quarticity which is an asymptotically unbiased estimator of integrated quarticity in the absence of microstructure noise. The $T Q_{t}=N \cdot \xi_{4 / 3}^{-3}$. $\sum_{i=3}^{N}\left|r_{t, i}\right|^{4 / 3} \cdot\left|r_{t, i-1}\right|^{4 / 3} \cdot\left|r_{t, i-2}\right|^{4 / 3}$ and converges in probability to integrated quarticity. Furthermore, as $N \rightarrow \infty$, then the $Z J_{t}^{(T B P V)} \rightarrow N(0,1)$. The $Z J_{t}^{(T B P V)}$ so-called jump ratio test is useful as a 'pre-test', prior to detecting jump components. The crucial point of this test stands that under the null hypothesis of no jumps, the difference between the estimators of variation of the total quadratic variation and continuous component should be close to 0 (see Duong and Swanson [2011]).

Applying the jump detection scheme which follows, we detect jump variation (henceforth jump) of the price prosses, at a daily frequency, based on the following condition:

$$
R J_{t}=\left|R V_{t}-T B P V_{t}\right| \cdot I_{\left\{Z J_{t}^{(T B P V)}>\Phi_{a}\right\}}
$$

where $I_{\{\cdot\}}$ is an indicator function of the $Z J_{t}^{(T B P V)}$ exceeding of a given critical value. Thus, a jump is considered to be significantly different from zero if the $Z J_{t}^{(T B P V)}$ exceeds the appropriate critical value of the standard Gaussian distribution, denoted by $\Phi_{a}$, at a $a$ level of significance.

\section{A.1.3 Realized Semi-Variances and Upside and Downside Jumps}

We estimate the downside (bad) and upside (good) semi-variance (realized volatility) in order to capture the sign asymmetry of the volatility process. These serve as measures of downside

\footnotetext{
${ }^{6}$ Following Corsi, Pirino, and Reno [2010], the local variance $\left(\widehat{V}_{t}^{Z}\right)$-which is estimated with a non-parametric filter of length $2 L+1$ which is iterated in $Z$ for $Z=1,2,3 \ldots$ - has a starting value of $\widehat{V}^{0}$ equal to $+\infty$. The $L$ is the bandwidth parameter which determines the number of adjacent intraday returns included in the estimation of the $\widehat{V}_{t}^{Z}$. In other words, this corresponds to using all available intraday observations in the first step. For the first step, the variable $c_{\theta}$ is set to be equal to 3 . However, in each step (iteration) large intraday returns are excluded by a condition. Finally, by multiplying each variance estimate with $c_{v}^{2}$, the threshold for the following step is obtained. The procedure stops after two or three iterations using intraday data (three in our case) (see the Appendix B in Corsi, Pirino, and Reno [2010] for further discussion).
} 
and upside risk, respectively. Following Barndorff-Nielsen, Kinnebrock, and Shephard [2010], we estimate the realized semi-variances as follows:

$$
\begin{aligned}
& R S_{t}^{-}=\sum_{i=1}^{N} r_{t, i}^{2} \cdot I_{\left\{r_{t, i}<0\right\}} \\
& R S_{t}^{+}=\sum_{i=1}^{N} r_{t, i}^{2} \cdot I_{\left\{r_{t, i}>0\right\}}
\end{aligned}
$$

where $r_{t, i}$ represents the 5 -minute return $i$ within a day $t$ and $i=(1, \ldots, N)$ and $N$ is the total number of intraday observations within a day $t$.

Then, following the suggestion of Duong and Swanson [2011] and Duong and Swanson [2015], we estimate the downside and upside jumps formulated by power transformation instead of decomposition using arbitrary truncation levels (as in the following sub-section). The downside and upside jumps are defined respectively, as follows:

$$
\begin{aligned}
& R J_{t}^{-}=I_{\left\{Z J_{t}^{(T B P V)}>\Phi_{a}\right\}} \cdot \sum_{i=1}^{N}\left|r_{t, i}\right|^{q} \cdot I_{\left\{r_{t, i}<0\right\}} \\
& R J_{t}^{+}=I_{\left\{Z J_{t}^{(T B P V)}>\Phi_{a}\right\}} \cdot \sum_{i=1}^{N}\left|r_{t, i}\right|^{q} \cdot I_{\left\{r_{t, i}>0\right\}}
\end{aligned}
$$

where the $q$ is the asymmetry variable and affects the limiting behavior of the estimator. In this paper, we are interested in the case where $q \geq 2$, since large values of $q$, are dominated by large jumps. For $q<2$, the jump variations are not always guaranteed to be finite. In our case, we selected $q$ equal to 2.5 .

After that, we can estimate the corresponding asymmetric jump as in Duong and Swanson [2011], as follows:

$$
R J A_{t}=I_{\left\{Z J_{t}^{(T B P V)}>\Phi_{\alpha}\right\}} \cdot\left\{R J_{t}^{+}-R J_{t}^{-}\right\}
$$

The $R J A_{t}$ is also so-called signed jump. A positive (negative) sign implies that the jump occurred in day $t$ is associated with events (e.g. news) which primarily affected the upside (downside) volatility, thus economic conclusions can be drawn e.g. testing the efficiency of an intervention policy from a market regulator.

In all cases, we use the same jump detection schemes similar to the previous section. Therefore, downside, upside and asymmetric jumps are considered to be significantly different from zero if the $Z J_{t}^{(T B P V)}$ exceeds the appropriate critical value at a $a$ significant level.

\section{A.1.4 Small and Large Jumps}

We also estimate large and small jump variations as in the study of Duong and Swanson [2011] using decomposition based on a fixed truncation level $(\gamma)$. Thus, the realized measure of truncated large jump variation, $R V L J_{t}$, based on a jump detection schemes used in previous cases, is given by the following condition:

$$
R V L J_{t}=\min \left\{R J_{t},\left(\sum_{i=1}^{N} r_{t, i}^{2} \cdot I_{\left\{\left|r_{t, i}\right| \geq \gamma\right\}}\right) \cdot I_{\left\{Z J_{t}^{(T B P V)}>\Phi_{\alpha}\right\}}\right\}
$$

where $R J_{t}$ is equal to $\left|R V_{t}-T B P V_{t}\right| \cdot I_{\left\{Z J_{t}^{(T B P V)}>\Phi_{a}\right\}}$, as estimated in equation (7). The selection of $\gamma$ is data driven. In this paper, following the suggestions of Duong and Swanson [2011] we select the $\gamma$ to be equal to 2 .

Finally, the realized measure of truncated small jump variation is $R V S J_{t}$ and is given by the following condition:

$$
R V S J_{t}=R J_{t}-R V L J_{t}
$$

\section{A.2. Causality-in-Quantiles Test}


This sub-section provides a brief description of the quantile based methodology based on the causality framework of Jeong et al. [2012]. Let $y_{t}$ denote either return, realized volatility, its good or bad versions, volatility jumps, and its various forms, i.e., good, bad, asymmetric, large and small jumps used in turn, and $x_{t}$ denote the predictor variable, in our case the dummies capturing wins or losses, again considered separately.

Formally, let $Y_{t-1} \equiv\left(y_{t-1}, \ldots, y_{t-p}\right), \quad X_{t-1} \equiv\left(x_{t-1}, \ldots, x_{t-p}\right), \quad Z_{t}=\left(X_{t}, Y_{t}\right), \quad$ and $F_{y_{t} \mid} \cdot\left(y_{t}, Z_{t-1}\right)$ and $F_{y_{t} \mid Y_{t-1}}\left(y_{t}, Y_{t-1}\right)$ denote the conditional distribution functions of $y_{t}$ given $Z_{t-1}$ and $Y_{t-1}$, respectively. If we denote the conditional quantiles $Q_{\theta}\left(Z_{t-1}\right) \equiv Q_{\theta}\left(y_{t} \mid Z_{t-1}\right)$ and $Q_{\theta}\left(Y_{t-1}\right) \equiv Q_{\theta}\left(y_{t} \mid Y_{t-1}\right)$, we have $F_{y_{t} \mid Z_{t-1}}\left\{Q_{\theta}\left(Z_{t-1}\right) \mid Z_{t-1}\right\}=\theta$ with probability one. Consequently, the (non)causality in the $\theta$-th quantile hypotheses to be tested can be specified as:

$$
\begin{aligned}
& H_{0}: P\left\{F_{y_{t} \mid Z_{t-1}}\left\{Q_{\theta}\left(Y_{t-1}\right) \mid Z_{t-1}\right\}=\theta\right\}=1 \\
& H_{1}: P\left\{F_{y_{t} \mid Z_{t-1}}\left\{Q_{\theta}\left(Y_{t-1}\right) \mid Z_{t-1}\right\}=\theta\right\}<1
\end{aligned}
$$

Jeong et al. [2012] employ the distance measure $J=\left\{\varepsilon_{t} E\left(\varepsilon_{t} \mid Z_{t-1}\right) f_{Z}\left(Z_{t-1}\right)\right\}$, where $\varepsilon_{t}$ is the regression error term and $f_{z}\left(Z_{t-1}\right)$ is the marginal density function of $Z_{t-1}$. The regression error $\varepsilon_{t}$ emerges based on the null hypothesis in (15), which can only be true if and only if $E\left[1\left\{y_{t} \leq\right.\right.$ $\left.\left.Q_{\theta}\left(Y_{t-1}\right) \mid Z_{t-1}\right\}\right]=\theta$ or, equivalently, $1\left\{y_{t} \leq Q_{\theta}\left(Y_{t-1}\right)\right\}=\theta+\varepsilon_{t}$, where $1\{\cdot\}$ is an indicator function. Jeong et al. (2012) show that the feasible kernel-based sample analogue of $J$ has the following form:

$$
\hat{J}_{T}=\frac{1}{T(T-1) h^{2 p}} \sum_{t=p+1}^{T} \sum_{S=p+1, s \neq t}^{T} K\left(\frac{Z_{t-1}-Z_{S-1}}{h}\right) \hat{\varepsilon}_{t} \hat{\varepsilon}_{s}
$$

where $K(\cdot)$ is the kernel function with bandwidth $h, T$ is the sample size, $p$ is the lag order, and $\hat{\varepsilon}_{t}$ is the estimate of the unknown regression error, which is estimated as follows:

$$
\hat{\varepsilon}_{t}=1\left\{y_{t} \leq Q_{\theta}\left(Y_{t-1}\right)\right\}-\theta
$$

$\hat{Q}_{\theta}\left(Y_{t-1}\right)$ is an estimate of the $\theta$-th conditional quantile of $y_{t}$ given $Y_{t-1}$ and we estimate $\hat{Q}_{\theta}\left(Y_{t-1}\right)$ using the nonparametric kernel method as:

$$
\hat{Q}_{\theta}\left(Y_{t-1}\right)=\hat{F}_{y_{t} \mid Y_{t-1}}^{-1}\left(\theta \mid Y_{t-1}\right)
$$

where $\hat{F}_{y_{t} \mid Y_{t-1}}\left(y_{t} \mid Y_{t-1}\right)$ is the Nadarya-Watson kernel estimator given by:

$$
\widehat{F}_{y_{t} \mid Y_{t-1}}\left(y_{t} \mid Y_{t-1}\right)=\frac{\sum_{s=p+1, s \neq t}^{T} L\left(\frac{\left(Y_{t-1}-Y_{s-1}\right)}{h}\right) 1\left(y_{s} \leq y_{t}\right)}{\sum_{s=p+1, s \neq t}^{T} L\left(\frac{\left(Y_{t-1}-Y_{S-1}\right)}{h}\right)}
$$

with $L(\cdot)$ denoting the kernel function and $h$ the bandwidth.

Note that, asymptotic normality of the $\hat{J}_{T}$ holds under $\beta$-mixing conditions for all the time series involved. In particular, the time series $x_{t}$ and $y_{t}$ should be strictly stationary and absolutely regular with mixing coefficients $\beta(\tau)=O\left(\rho^{\tau}\right)$ for some $0<\rho<1$. $\hat{J}_{T}$ is a second order degenerate $U$-statistic indexed by parameters and the asymptotic normal distribution of the second order degenerate $U$-statistic for weakly dependent data is established in Fan and $\mathrm{Li}$ [1999] and $\mathrm{Li}$ [1999].

The empirical implementation of causality testing via quantiles entails specifying three important choices: the bandwidth $h$, the lag order $p$, and the kernel type for $K(\cdot)$ and $L(\cdot)$ respectively. In this study, we use $p=1$ for the entire sample is based on the SIC. The bandwidth value is chosen by employing the least squares cross-validation techniques over the entire sample period. Finally, for $K(\cdot)$ and $L(\cdot)$ Gaussian-type kernels was employed, i.e., their respective probability density functions follows a standard normal distribution. 


\section{Appendix B}

Table B1. Summary Statistics

\begin{tabular}{|l|r|r|r|r|r|r|r|r|r|r|}
\hline \multicolumn{10}{|c|}{ Variables } \\
\hline Statistic & \multicolumn{1}{|c|}{$r$} & \multicolumn{1}{c|}{$R V$} & \multicolumn{1}{c|}{$R J$} & \multicolumn{1}{c|}{$R S^{-}$} & \multicolumn{1}{c|}{$R S^{+}$} & \multicolumn{1}{c|}{$R J^{-}$} & $R^{+}$ & $R J A$ & $R V L J$ & $R V S J$ \\
\hline Mean & 0.0307 & 1.1099 & 0.0443 & 0.9187 & 0.7918 & 0.0394 & 0.0156 & -0.0238 & 0.2264 & 0.2092 \\
\hline Median & 0.1007 & 0.5610 & 0.0000 & 0.3231 & 0.3068 & 0.0000 & 0.0000 & 0.0000 & 0.0000 & 0.0000 \\
\hline Maximum & 6.9096 & 79.1496 & 12.3791 & 144.3269 & 40.8237 & 41.6626 & 6.5821 & 1.0079 & 40.7482 & 26.0223 \\
\hline Minimum & -11.3453 & 0.0088 & 0.0000 & 0.0027 & 0.0049 & 0.0000 & 0.0000 & -35.0805 & 0.0000 & 0.0000 \\
\hline Std. Dev. & 1.4324 & 2.4435 & 0.2793 & 3.9368 & 2.0188 & 0.9095 & 0.1403 & 0.7886 & 0.9768 & 0.7272 \\
\hline Skewness & -0.6037 & 16.5951 & 34.5407 & 24.0290 & 9.2649 & 41.1151 & 40.5116 & -39.5799 & 28.9953 & 19.3844 \\
\hline Kurtosis & 8.6688 & 449.7622 & 1484.8450 & 765.6202 & 123.9778 & 1787.8280 & 1868.1110 & 1648.8260 & 1157.9790 & 628.3937 \\
\hline Jarque-Bera & 3605.656 & 21541587 & $2.36 \mathrm{E}+08$ & 62671844 & 1607746 & $3.43 \mathrm{E}+08$ & $3.74 \mathrm{E}+08$ & $2.91 \mathrm{E}+08$ & $1.44 \mathrm{E}+08$ & 42141245 \\
\hline$p$-value & 0.0000 & 0.0000 & 0.0000 & 0.0000 & 0.0000 & 0.0000 & 0.0000 & 0.0000 & 0.0000 & 0.0000 \\
\hline Observations & \multicolumn{19}{|c|}{2576} & & & \\
\hline
\end{tabular}

Note: See Notes to Table 1. Std. Dev. stands for standard deviation, while probability is the $p$-value for the Jarque-Bera test, with the null hypothesis of normality. 
Table B2. Causality-in-Quantiles Results for the Stock Market of Pakistan

\begin{tabular}{|c|c|c|c|c|c|c|c|c|c|c|c|c|}
\hline \multirow{2}{*}{$\begin{array}{l}\text { Dependent } \\
\text { variable }\end{array}$} & \multirow{2}{*}{$\begin{array}{l}\text { Independent } \\
\text { variable }\end{array}$} & \multicolumn{11}{|c|}{ Quantile } \\
\hline & & 0.05 & 0.10 & 0.20 & 0.30 & 0.40 & 0.50 & 0.60 & 0.70 & 0.80 & 0.90 & 0.95 \\
\hline \multirow{2}{*}{$r$} & Win & $1.81 *$ & $4.78 * * *$ & $4.83 * * *$ & $4.25 * * *$ & $2.53 * *$ & $2.35^{* *}$ & $2.41 * *$ & $1.95^{*}$ & $3.01 * * *$ & $3.14 * * *$ & $1.69^{*}$ \\
\hline & Loss & $1.68 *$ & $4.35 * * *$ & $4.99 * * *$ & $4.94 * * *$ & $2.99 * * *$ & $2.58 * * *$ & $2.87 * * *$ & $2.11 * *$ & $2.89 * * *$ & $3.22 * * *$ & $1.83^{*}$ \\
\hline \multirow{2}{*}{$R V$} & Win & 0.15 & 0.47 & 1.32 & $2.19 * *$ & $3.20 * * *$ & $2.87 * * *$ & $1.95 *$ & 1.19 & 0.56 & 0.19 & 0.05 \\
\hline & Loss & 0.16 & 0.42 & 1.25 & $2.24 * *$ & $3.15 * * *$ & $2.91 * * *$ & $2.05^{* *}$ & 1.44 & 0.65 & 0.17 & 0.05 \\
\hline \multirow{2}{*}{$R J$} & Win & $1454.29 * * *$ & $872.11 * * *$ & $418.51 * * *$ & $205.73 * * *$ & $85.84 * * *$ & $21.36^{* * *}$ & 0.28 & 0.27 & 0.27 & 0.37 & 0.28 \\
\hline & Loss & $1501.72 * * *$ & $902.38 * * *$ & $435.41 * * *$ & $215.97 * * *$ & $91.72 * * *$ & $24.00 * * *$ & 0.36 & 0.25 & 0.25 & 0.27 & 0.22 \\
\hline \multirow{2}{*}{$R S^{-}$} & Win & 0.01 & 0.03 & 0.08 & 0.09 & 0.15 & 0.21 & 0.24 & 0.25 & 0.27 & 0.19 & 0.09 \\
\hline & Loss & 0.01 & 0.04 & 0.10 & 0.15 & 0.20 & 0.29 & 0.31 & 0.34 & 0.25 & 0.16 & 0.09 \\
\hline \multirow{2}{*}{$R S^{+}$} & Win & 0.07 & 0.24 & 0.72 & 1.35 & $1.66^{*}$ & $2.12 * *$ & $1.89^{*}$ & 1.16 & 0.62 & 0.20 & 0.07 \\
\hline & Loss & 0.08 & 0.24 & 0.67 & 1.13 & 1.59 & $2.13^{* *}$ & $1.78 *$ & 1.09 & 0.66 & 0.23 & 0.10 \\
\hline \multirow{2}{*}{$R J^{-}$} & Win & $1988.49 * * *$ & $1181.63^{* * * *}$ & $561.74 * * *$ & $274.29 * * *$ & $113.48 * * *$ & $27.56 * * *$ & 0.08 & 0.23 & 0.25 & 0.25 & 0.24 \\
\hline & Loss & $2045.71 * * *$ & $1218.59 * * *$ & $583.15^{* * * *}$ & $287.88^{* * * *}$ & $121.72 * * *$ & $31.53^{* * *}$ & 0.20 & 0.20 & 0.34 & 0.33 & 0.22 \\
\hline \multirow{2}{*}{$R J^{+}$} & Win & $1456.53^{* * *}$ & $874.35 * * *$ & $420.18 * * *$ & $206.89 * * *$ & $86.59 * * *$ & $21.75 * * *$ & 0.32 & 1.50 & $1.81^{*}$ & $1.93 *$ & $1.67^{*}$ \\
\hline & Loss & $1503.71 * * *$ & $904.48 * * *$ & $437.02 * * *$ & $217.11 * * *$ & $92.48 * * *$ & $24.41 * * *$ & 0.41 & 1.17 & 1.41 & $1.75 *$ & 1.46 \\
\hline \multirow{2}{*}{$R J A$} & Win & 0.02 & 0.02 & 0.01 & $1063.87 * * *$ & $651.86^{* * * *}$ & $373.52 * * *$ & $182.85 * * *$ & $60.48 * * *$ & $2.84 * * *$ & 0.01 & 0.02 \\
\hline & Loss & 0.02 & 0.02 & 0.07 & $1066.89^{* * *}$ & $654.24 * * *$ & $375.33 * * *$ & $184.15 * * *$ & $61.24 * * *$ & $3.00 * * *$ & 0.01 & 0.04 \\
\hline \multirow{2}{*}{$R V L J$} & Win & $2257.65 * * *$ & $1346.57 * * *$ & $641.34 * * *$ & $312.76 * * *$ & 128.76 *** & $30.74 * * *$ & 0.09 & 0.05 & 0.15 & 0.20 & 0.15 \\
\hline & Loss & $2313.89 * * *$ & $1383.20 * * *$ & $662.84 * * *$ & $326.58 * * *$ & $137.23 * * *$ & $34.83 * * *$ & 0.12 & 0.21 & 0.39 & 0.26 & 0.17 \\
\hline \multirow{2}{*}{$R V S J$} & Win & $1882.88 * * *$ & $1118.69^{* * *}$ & $534.67 * * *$ & $264.15 * * *$ & $112.04 * * *$ & $29.36^{* * *}$ & 0.34 & 0.39 & 1.60 & 0.97 & 0.50 \\
\hline & Loss & $1943.05^{* * *}$ & $1157.55^{* * *}$ & $557.20 * * *$ & $278.48 * * *$ & 120.80 *** & $33.69 * * *$ & 0.73 & 0.35 & 1.25 & 0.82 & 0.49 \\
\hline
\end{tabular}

Note: See Notes to Table 1; DV (IV) stands for dependent variable (independent variable); The entries correspond to the standard normal $\hat{J}_{T}$ statistic which tests whether Win or Loss Granger causes the various stock market variables at a specific quantile. ${ }^{* * *},{ }^{* *},{ }^{*}$ indicates rejection of the null hypothesis of no-causality at 1 , 5 and $10 \%$ levels of significance respectively., with corresponding critical values of 2.575, 1.96 and 1.645 . 